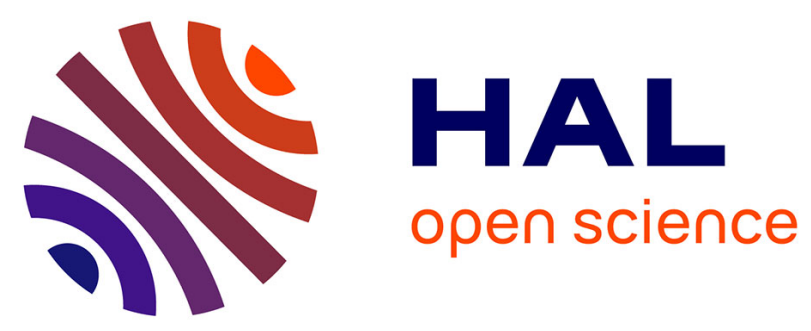

\title{
Patterns of selective serotonin reuptake inhibitor use andrisk of falls and fractures in community-dwelling elderly people. The Three-City cohort
}

Isabelle Carrière, Amandine Farré, Joanna Norton, Marilyn Wyart, Christophe Tzourio, Pernelle Noize, Karine Pérès, Annie Fourrier-Réglat, Marie-Laure Ancelin

\section{To cite this version:}

Isabelle Carrière, Amandine Farré, Joanna Norton, Marilyn Wyart, Christophe Tzourio, et al.. Patterns of selective serotonin reuptake inhibitor use andrisk of falls and fractures in community-dwelling elderly people. The Three-City cohort. Osteoporosis International, 2016, 27 (11), pp.3187-3195. 10.1007/s00198-016-3667-7 . inserm-01481363

\section{HAL Id: inserm-01481363 https://www.hal.inserm.fr/inserm-01481363}

Submitted on 2 Mar 2017

HAL is a multi-disciplinary open access archive for the deposit and dissemination of scientific research documents, whether they are published or not. The documents may come from teaching and research institutions in France or abroad, or from public or private research centers.
L'archive ouverte pluridisciplinaire HAL, est destinée au dépôt et à la diffusion de documents scientifiques de niveau recherche, publiés ou non, émanant des établissements d'enseignement et de recherche français ou étrangers, des laboratoires publics ou privés. 
Patterns of selective serotonin reuptake inhibitor use andrisk of falls and fractures in community-dwelling elderly people. The Three-City cohort

Isabelle Carrière ${ }^{1,2}$, Amandine Farré ${ }^{1,2}$, Joanna Norton ${ }^{1,2}$, Marilyn Wyart ${ }^{3}$, Christophe Tzourio ${ }^{4,5}$, Pernelle Noize $^{4,6}$, Karine Pérès ${ }^{4,5}$, Annie Fourrier-Réglat ${ }^{4,6,7}$, Marie Laure Ancelin ${ }^{1,2}$

${ }^{1}$ Inserm, U1061, Montpellier, France.

${ }^{2}$ Univ. Montpellier, U1061, Montpellier, France.

${ }^{3}$ Department of Psychiatry, CHU Caremeau, Nîmes, France.

${ }^{4}$ Inserm,ISPED, centreU1219 - Bordeaux Population Health Research Center, Bordeaux, France.

${ }^{5}$ Univ. Bordeaux, ISPED, Centre Inserm U1219 - Bordeaux Population Health Research Center, Bordeaux, France.

${ }^{6}$ Department of Clinical Pharmacology, CHU Bordeaux, Bordeaux, France.

${ }^{7}$ Univ. Bordeaux, U1219, Bordeaux, France

Address for correspondence:

Dr Isabelle Carrière

Inserm U1061, Neuropsychiatry: epidemiological and clinical research.

39 avenue Charles Flahault, BP 34493,

34093 Montpellier cedex 05, France

Email: isabelle.carriere@inserm.fr

Tel: +33 499614 691, Fax: +33499614 579

Abbreviated title: SSRIs and risk of falls and fractures 


\begin{abstract}
Purpose: Increased risk of falls and fractures has been reported in elderly users of selective serotonin reuptake inhibitors (SSRIs). However, biases were insufficiently addressed notably temporality between exposure and outcome and confounding by residual depression. Our objective was to examine the associations between SSRIs and fall or fracture incidence focusing on their chronic use and different types of SSRIs.
\end{abstract}

Methods: The population-based cohort included participants aged 65 years and above, who had not fallen before inclusion $(n=6,599)$ or free of recent fracture $(n=6823)$ and followed-up twice over 4 years. New fall and fracture events wereself-reported anddefined as at least two fallsand onefracture, respectively, during the previous 2years. SSRIusers were compared with those taking noantidepressants. Hazard ratios (HR) were estimated using Cox models with delayed entry and adjusted for many confounders including residual depressive symptoms. Results: Incidence of falls was $19.3 \%$ over 4 years and that of fractures $9.5 \%$. After multi-adjustment,SSRI intake was significantly associated with a higher risk of falls(HR, 95\% CI $=1.58,1.23-2.03)$ and fractures $(\mathrm{HR}$, $95 \% \mathrm{CI}=1.61,1.16-2.24)$. The risksweresignificantly increased by $80 \%$ in those continuing the treatment over 4 years. Citalopram intake only wasatsignificantrisk for falls and fluoxetine for fractures.

Conclusions: In this large community-dwelling elderlysample, SSRI users were at higher risk of falls and fractures. This association wasnot due to reverse causality or residual depressive symptoms.Different SSRI drugs may have specific adverse effects on falls and fractures.

\title{
Summary:
}

In this population-basedelderly cohort,participants using selective serotonin reuptake inhibitor (SSRI) antidepressants have an increased risk of falls and fractures notably when the treatment was continued over 4 years. Among the various SSRI types citalopram only was at significant risk for falls and fluoxetine for fractures.

Key words:elderly, antidepressants, falls, fractures 


\section{Introduction}

Antidepressants are among the most commonly prescribed drugs in the Western world, with an annual rate of treatment of 10.1 per 100 persons in the US general population and 13.7 in the elderly[1]. While there are arguments supporting antidepressant effectiveness and favorablebenefit-risk ratio for major depression[2],a much lower efficacy has been found for moderate depression[3].Data on depression inelderly people are scarce despite specific characteristics including the chronicity of symptoms[4], frequent comorbidities and the high prevalence of subsyndromal depression[5]whichmay be inadequately treated. Over-treatment of subsyndromal depression may increase risk of drug interactions and adverse reactions as aging is also associated with pharmacodynamic alterations (decreased renal clearance, altered hepatic metabolism and increased elimination half-lives).

Several meta-analyses and reviews have reported an increased risk of falls in the elderly[6-9] as well as fractures[10, 11], although not consistently. However,biases are insufficiently addressed notably due to a lack or limited consideration of (i) criteria of temporality between exposure and outcome,(ii) pattern of use andtreatment chronicity and(iii) potential confounders and channeling bias (related to underlying burden of physical and mental illness).Separating the effect of depression from the effect of treatment is notably a critical point [11]. While most of the earlier studies found the class oftricyclic antidepressants (TCAs)to be a riskfactor for fallsand fractures[8, 12], more recentstudies focused on selective serotonin reuptake inhibitors (SSRIs)[13, 14]which are now first-line therapy among older patients. Although being considered safer than TCAs, SSRIs have been found to be associated with an increased risk of bone mineral density loss andfracture[10, 15-17].This led to consider SSRIs as potentially inappropriate in older adults with a history of falls or fractures[18].However, tworecent systematic reviewsconcluded that evidence of causationwas lacking due to the absence of a demonstrated mediating pathway between SSRIs and falls[19] or osteoporosis[20].As the effects of antidepressants on falls and fractures in elderly people have never been evaluated in randomized clinical trials, only well-designed analyses of large population-based cohortscan help address theserelationships, evaluating long-term effects and taking into account the temporality between exposure and outcome andthe main confounders.

The purpose of this study was to examine the longitudinal associations between antidepressant use and (i) falls and(ii) fractures, in a large elderly community-dwelling cohort, for which information on a wide range of potential confounding factors including residual depressive symptoms was available. The analyses focused on SSRIs, their chronic use and different types of SSRIs. 


\section{Method}

\section{Study sample}

Subjects were recruited as part of a multi-site cohort study of community-dwelling persons aged 65 years and over from the electoral rolls of three French cities (Bordeaux, Dijon, and Montpellier) between 1999 and 2001[21]. The study protocol was approved by the Ethical Committee of the Bicetre University-Hospital (France) and written informed consent was obtained from each participant. A standardized evaluation with a face-to-face interview and a clinical examination was undertaken at baseline and after 2 and 4 years. The followup was then extended but data on falls were not collected after 4 years. Of the 9,294 participants included in the cohort, 503 were excluded because of a diagnosis of prevalent or incident dementia. The incidence study on falls was carried out on 6,599 participants, after further excluding 600 who declared at least 2 falls before inclusion, 908 with no follow-up assessments, 214 treated with other antidepressants(only SSRI antidepressants were considered in the present study) and 470 with missing data for at least one of the 16adjusting covariates. The incidence study on fractures was performed on 6,823 participants, after further excluding 613 who declared a fracture before inclusion, 1,087 with no follow-up assessments, 216 treated with other antidepressants and 52 with missing data for at least one of the 9adjusting covariates.

Compared with the analyzed sample for fall incidence, those excluded were older $(\mathrm{p}<.001)$, more frequently women $(\mathrm{p}=0.002)$, non-smokers $(\mathrm{p}<.001)$ and takingother medications $(\mathrm{p}<.001)$. They had more often cognitive, visual andhearing impairment, physical and activity limitations, fear of falling, daytime sleepiness, depressive symptoms, cardiovascular diseases, osteo-articular pains and orthostatic hypotension ( $\mathrm{p}<.001$ for all comparisons).

\section{Outcomes}

At baseline, participants were asked about the occurrence of falls during the preceding months andat follow-up examinations about the occurrence of falls since the preceding examination. Participants who reported having fallen were asked about the number of falls. At each follow-up visit those who reported at least 2 falls in the last 2 years were classified as fallers.

For fractures, participants were asked identicallyat baseline and at each follow-up examination about the occurrence of fractures with andwithout hospitalization, during the 2 preceding years. All body sites were considered: hip, wrist, spine (including compression), upper limb (arm, shoulder and collarbone), lower limb and any other site. The outcome was defined as reporting at least one fracture in the last 2 years. 


\section{Antidepressant exposure}

At baseline and follow-up examinations, the questionnaire included an inventory of all drugs regularly used during the preceding month. To reduce underreporting, participants were asked to provide medical prescriptions, drug packages and any other relevant material. Drug exposure has previously been validated in this cohort in comparison with the reimbursement data from the health care insurance system[22, 23].The drugs were systematically coded using the Anatomical Therapeutic Chemical (ATC) classification system.Participants treated with antidepressants other than SSRIs wereexcluded from the analyses. SSRI drugs included: citalopram (N06AB04), fluoxetine (N06AB03),fluvoxamine (N06AB08), paroxetine (N06AB05), andsertraline (N06AB06).

We also examined the chronicityof use over the 4 years of follow-up;the analysis compared the group of participants reporting SSRI use at baseline and at both follow-up visits (the group is referred to hereafter as the "continuing group") and the group of those reporting SSRI use only at baseline ("discontinuing group") with the group of those never treated with any antidepressants ("never users").

\section{Socio-demographic and clinical variables}

The standardized interview included questions on socio-demographic characteristics, smoking, visual and hearing impairment,difficulties standing up from a chair, problems of balance during walking, fear of falling, excessive daytime sleepiness, and cardiovascular pathologies. Osteo-articular pain included reported pain or treatment with anti-inflammatory or antirheumatic agents.Use of benzodiazepines andother drugsacting on the central nervous system (CNS) as well as the total number of other medications werederived from reported drugs. For the fracture study, use of anti-osteoporosis drugs (calcium, bisphosphonates, vitamin D, calcitonin, raloxifene and teriparatide), hormonal replacement therapy and corticosteroids were also considered. A hierarchical indicator of disability[24]combined three scales: Rosow and Breslau mobility scale[25],LawtonBrody Instrumental Activity of Daily Living (IADL) scale[26] and Katz's Activity of Daily Living (ADL) scale[27].This indicator defines4 levels of disability: full independence, mild disability (only mobility restriction), moderate disability (mobility and IADL restriction), and severe disability (mobility, IADL and ADL restriction).Cognitive impairment was defined as a Mini Mental State Examination (MMSE) score<26[28].Severity of depressive symptoms was assessed by the Center for Epidemiologic StudiesDepression scale (CES-D)[29] and history of major depressive episode (MDE) was diagnosed using the Mini International Neuropsychiatric Interview[30].Orthostatic hypotension was defined as a blood pressure reduction of at least $20 \mathrm{mmHg}$ systolic or $10 \mathrm{mmHg}$ diastolic between lying and standing position. Low standing blood 
pressure (LSBP)was defined as $\leq 90 / 60 \mathrm{mmHg}$ [31] andbody mass index (BMI) as weight divided by height squared.

\section{Statistical analyses}

Comparison of baseline characteristics between included and excluded participants was performed using Chisquare tests and Wilcoxon rank-sum tests. Two main outcomes were examined in this study,i.e. the occurrences of falls and fractures. To avoid reverse causality and clarify temporality we only consideredthe subjects who did not report the outcomeof interest in theperiodpreceding inclusion. The risk associated with SSRI use was evaluated using Cox models with delayed entry taking age as the basic time scale and birth as the time origin. Results were expressed as hazard ratios (HR) with 95\% confidence intervals (CI). This method enables a better adjustment for age and is preferred, especially for an elderly sample, over the standard model which uses study time as the time scale[32].The assumptions of proportional hazards over time and the linearity of continuouscovariates were verified.

To control for confounding effects, three nested models were constructed. Model 0 was adjusted for gender, centre and age (time scale). Model 1 included additional covariates that were associated with fall or fracture incidence ( $\mathrm{p}<0.20$ in Model 0). This model thus included 14 and 7 additional covariates for fall and fracture outcomes, respectively. Model 2 further included potentialmediators such as poor balance and daytime sleepiness. These models were performed for participants with no missing data on any of the covariates.Allanalyses were conducted using the statisticalsoftwareSAS version 9.4 for Windows. 


\section{Results}

The median time of follow-up (interquartile range) was 3.6 (3.4-3.8) years. Regarding falls, $19.3 \%$ of the 6,599 participants declared having fallen at least twice at the 2-year (10.2\%) or 4-year follow-up (9.1\%). The differences between fallers and non-fallers adjusted for age, sex, and center are shown in Table 1. Nearly allbaseline characteristics were associated with fall incidence,except for visual impairment,orthostatic hypotension, LSBP, and benzodiazepine use. Regarding fractures, $9.5 \%$ of the 6,823 participants had at least one fracture over the follow-up: $4.5 \%$ at 2 years and $5.0 \%$ at 4 years. Table 2 presents the differences between participants who reported a fracture and those who did not. Participants with incident fracture were significantly older, more often women, non-smokers, users of CNS and anti-osteoporosis drugs and had more frequently a history of MDE.

Table 3gives the risk of fallsat follow-up for baseline SSRI intake compared with no antidepressant intake. The same pattern of associations was found in minimally adjusted (Model 0) and multi-adjusted (Model 1)models. SSRI intake was significantly associated with a higher risk of falls (HR, 95\% CI $=1.58,1.23-2.03)$.Further adjustments for possible mediators (poor balance during walking and daytime sleepiness) did not change the results $(\mathrm{HR}, 95 \% \mathrm{CI}=1.62,1.23-2.12, \mathrm{p}<0.001)$. No interaction was found between SSRI intake and gender $(\mathrm{p}=0.44)$.In the analysis by SSRI drugs, citalopram was associated with the highest adjusted hazard ratio for falls $(\mathrm{HR}, 95 \% \mathrm{CI}=2.31,1.35-3.96)$ although it was not the most commonly prescribed SSRI.We then examined the risk of falls according to the pattern of SSRI use during the 4 years. Compared to the group of "never users" an increased adjusted risk of falls at 4 years was found for the "continuing group" (HR, 95\% CI = 1.88, 1.36-2.61); the association was not significant for the "discontinuing group".

Baseline SSRI intake was also associated with an increased 4-year risk of fracture (Table 4) after multiple adjustments $(\mathrm{HR}, 95 \% \mathrm{CI}=1.61,1.16-2.24)$; further adjusting for poor balance did not modify the result (HR, $95 \% \mathrm{CI}=1.63,1.18-2.27)$. No interaction was found between SSRI use and gender $(\mathrm{p}=0.60)$ or anti-osteoporosis drug use ( $\mathrm{p}=0.22)$. The most prescribed SSRI drugs were paroxetine and fluoxetine, however only fluoxetine was associated with a two-fold increase in the risk of fractures (multi-adjusted HR, 95\% CI $=2.07,1.28-3.32$ ). In the multivariate analysis of the fracture risk according to the pattern of SSRI use during the 4 years, compared to the group of "never users", an increased risk was found for the "continuing group" $(\mathrm{HR}, 95 \% \mathrm{CI}=1.78,1.15-$ 2.78). 


\section{Discussion}

In this large prospective study,we found avery significant increase of about $60 \%$ in the 4 -year risk of fallsand fractures for participants taking SSRIsat baseline and an even greater increase (around 80\%) inchronic users. These associations remained significant after adjustment for a large range of other confounders. Conversely, the risk was not significant after treatment discontinuation. Examining individual SSRI drugs, a more than two-fold increased risk was found for falls in citalopram users only and for fracturesin fluoxetine users.

A higher risk of falling has already been reported with SSRIsin distinct settings; a nursing home sample[33], elderly patients from a primary care database[13]and community-dwelling older women[34].Falls are highly multi-factorial and in contrast with most previous studies, we adjusted for a large range of potential confounders including disability, difficulties standing up from a chair, osteo-articular pain, fear of falling, systolic blood pressure,cardiovascular diseases as well as use of benzodiazepines,other CNS drugs, and polymedication. As depression is a well-known risk factor for falls we also adjusted for residual depressive symptoms (including low energy, fatigue, attention difficulties,...)and severity using a validated scale and a diagnostic instrument for lifetime MDE.We actually found that depressive symptomatology was the main confounder together with fear of falling and disability which have rarely been considered before.In our multi-adjusted analysis, the hazard ratio for SSRI users remainedhigh andsignificant suggesting that the SSRIs themselves rather than the underlying burden of illness are independently associated with the risk of falls.

This effect on falls appeared loweredin participants who discontinued treatment in the first two years.Other findings showedthat regardless of the antidepressant class, the risk of falls increased shortly after treatment initiation and then decreased,with a peak within 8 months for SSRIs[16].In this elderly sample, fluoxetine and paroxetine were the most frequently prescribed antidepressants and although fluoxetine has the highest half-life elimination time, we found no significant differences for the risk of fallsbetween these twoSSRIs (data not shown).Conversely, despite lower statistical power, the risk of falling with citalopram was highly significant. This has also been reported in elderly patients from a primary care database[13], and further stresses that different SSRI drugs may have distincteffects on the risk of falls.

The temporality and possible reversibility of the risk after treatment discontinuation observed in this longitudinal study, together with the consistency of the associations in different populations and settings and possible doseeffects[35],lend support to a causative linkbetweenSSRIs and falls in the elderly. We hypothesized a number of reasons for this effect. Serotonergicadverse effects includedigestive symptoms, headache, restlessness, tremors, dizziness,anxiety andweakness[6, 36],SSRIsalso have sedative effects but this is lessfrequent than in patients 
taking TCAs[37].Poor sleep efficiencyiscommon with SSRIs, with long sleep latency and sleep fragmentation, resulting in multiple long wake episodes[38] whichcould leadto elderlypeople getting out of bedatnight,thus increasing the risk offalls. Visual function is also a key risk factor for falls[39] andSSRIsmay be associated with adverse ocular effects[40].In our large cohort we were able for the first time to examine many of these potential mediating factors, e.g.orthostatic hypotension, LSBP, poor balance and daytime sleepiness, visual impairmentas well as headache, anxiety and osteoporosis (data not shown) but they all failed to explain even partially the observed relationships.

Long-term SSRI treatment has been linked to osteoporosis in late-life[41] which together with fallsisa common pathway leading to fractures. A higher risk of fractures has previously been reported in SSRI users, with a duration- and dose- dependent effect; the higher the doses, the longer the use, and the higher the risk[10, 11, 14, 42, 43].However, most studies using administrative data, could not fully control for important confounders such as osteoporosis and related factors, e.g.use of anti-osteoporosis drugs and supplements (e.g., calcium, vitamin D or hormone therapy in women) and smoking. The role of depression has also not been taken into account.However, people with long-term history of depression may have lower physical activity or performances and poorer nutritional status which could be associated with fractures[44].In our study, we were able to adjust for both history of depression, behavioral characteristics, and use of anti-osteoporosis drugs and supplements, yet SSRI use was still associated with a $60 \%$ increasedrisk offractures, reaching $80 \%$ in long-term users.Theseresults thus provide further support for a causative link between SSRI intake and fractures in community-dwelling elderly people. We also found that fluoxetine increased therisk of fracturesbut not paroxetine which was just as frequentlyprescribed. The fact that citalopram was a risk factor for falls and fluoxetine for fractures remains to be elucidated butsuggests that fractures are not a simple consequence of falling and couldindicate differences in the nature and severity of adverse reactions.

Serotonin is found in blood platelet, gastrointestinal tract and the CNS and has been implicated in various physiological functions. Peripheral serotonin has been implicated in platelet aggregation, vascular tone, hypertension, and intestinal motility. In CNS, serotonin has been associated with mood, temperature regulation, circadian rhythm, vomiting, and energy balance. Regulation of bone metabolism is complex, involving different signaling pathways and opposite functions. Brain-derived serotonin increases osteoblast numbers and decreases bone resorption, therefore increasing bone mass. Conversely, gut-derived serotonin acts to inhibit bone formation and increased circulating serotonin has been associated with lower bone density[45].Age-related 
changes in drug absorption, metabolism, and blood-brain barrier permeability may also influence levels of serotonin. Depending on their pharmacological properties and bioavailability, and degree of serotonin reuptake inhibition,SSRIs may have distinct effects on bone.

Strengths of this study include itsmulticentric longitudinal design and the size of the sample with more than 6,500 elderly participants from the general population. Antidepressant use was ascertainedat baseline and during follow-upby examining the prescriptions and boxes, thus minimizing exposure misclassification. Exposure to both current and chronic antidepressant medication has previously been shown within this cohort to be highly valid in comparison with the reimbursement data from the health care insurance system[22, 23]. Although in observational studies residual confounding may always subsist, our analyses overcame several limitations of previous studies. History of falls or fractures can be both a predictor and a possible risk factorfor depression and studies are exposed to reverse causality. In our longitudinal study the temporality of the associations has been addressed by excluding the participants with fallsor fractures in the periodpreceding inclusion and restricting analyses to incident falls or fractures. To our knowledge this is also the first study which adjusted for such a large range of differentkey factorsincluding blood pressure, physical and activity limitations as well as physical and mental health.

Our study has several limitations. As in most previous observational studies, falls and fractures were selfreported. We however excluded prevalent and incident cases of dementia to avoid unreliable responses and potential overestimation of the association since behavioral disturbances in dementia are a major cause of falls. In addition, incident falls were retrieved from 2 questions and covered a 2-year period which may lead to underreporting. No data were available on the duration of the treatment before inclusion but we were able to evaluate the effect of long-term treatment during the follow-up.Poor balance and daytime sleepiness were also selfreported. We were not able to consider specific insomnia criteria such asfrequent night awakenings and also some aspects of the visual functioning including contrast vision.Another potential limitation is that we did not use propensity score methods in our analyses to account for confounders. However, it should be noted that these methods do not always adequately account for unmeasured confounders. They estimate marginal effects at a population level while multivariate models as used in this study estimate individual conditional effects [46] and are more suitable for explanatoryinvestigations with the additional advantage of allowing the evaluation of the impact of mediating factors. 
In conclusion, this study showed that in community-dwelling elderly people,SSRI users are at high risk of falls and fractures. These associationsare not due to reverse causality or residual depressive symptoms. The possible pathways explaining these associations remain to be explored. Differences may exist between SSRI drugs regarding the risk of falls and fractures. Precautionstaken whenprescribing TCAstoelderly patientsshould be extended to SSRIs along with an objective diagnosis of depression, an adapted treatmentand an evaluation of risk factors for falls and fractures. 


\section{Acknowledgments:}

The 3C Study is conducted under a partnership agreement between the Institut National de la Santé et de la Recherche Médicale (Inserm), Victor-Segalen Bordeaux II University, and Sanofi- Aventis. The 3C-Study was also supported by the Caisse Nationale d'Assurance Maladie des Travailleurs Salariés, Direction Générale de la Santé, MGEN, the Institut de la Longévité, Agence Française de Sécurité Sanitaire des Produits de Santé, the Regional Governments of Aquitaine, Bourgogne and Languedoc-Roussillon, the Fondation de France, the Ministry of Research-Inserm Programme 'Cohorts and collection of biological material', Novartis and the Fondation Plan Alzheimer

This work was supported by the Fondation pour la Recherche Médicale under the program "Iatrogénie des Médicaments", project "ELIANE-DEP - IMD20131229108".

Sponsor's Role: The funders had no role in study design, data collection and analysis, decision to publish, or preparation of the manuscript.

\section{Conflicts of interest:}

Isabelle Carrière, Amandine Farré, Joanna Norton, Marilyn Wyart, Christophe Tzourio, Pernelle Noize, Karine Pérès, Annie Fourrier-Réglat, and Marie Laure Ancelin declare that they have no conflict of interest. 


\section{References}

1. Olfson M, Marcus SC (2009) National patterns in antidepressant medication treatment. Arch Gen Psychiatry 66:848-856.

2. Cipriani A, Furukawa TA, Salanti G, Geddes JR, Higgins JP, Churchill R, Watanabe N, Nakagawa A, Omori IM, McGuire H, Tansella M, Barbui C (2009) Comparative efficacy and acceptability of 12 newgeneration antidepressants: a multiple-treatments meta-analysis. Lancet 373:746-758.

3. Kirsch I, Deacon BJ, Huedo-Medina TB, Scoboria A, Moore TJ, Johnson BT (2008) Initial severity and antidepressant benefits: a meta-analysis of data submitted to the Food and Drug Administration. PLoS Med $5: \mathrm{e} 45$.

4. Carriere I, Farre A, Proust-Lima C, Ryan J, Ancelin ML, Ritchie K (2016) Chronic and remitting trajectories of depressive symptoms in the elderly. Characterisation and risk factors. Epidemiol Psychiatr Sci 111.

5. Meeks TW, Vahia IV, Lavretsky H, Kulkarni G, Jeste DV (2011) A tune in "a minor" can "b major": a review of epidemiology, illness course, and public health implications of subthreshold depression in older adults. J Affect Disord 129:126-142.

6. Darowski A, Chambers SA, Chambers DJ (2009) Antidepressants and falls in the elderly. Drugs Aging 26:381-394.

7. Hartikainen S, Lonnroos E, Louhivuori K (2007) Medication as a risk factor for falls: critical systematic review. J Gerontol A Biol Sci Med Sci 62:1172-1181.

8. Leipzig RM, Cumming RG, Tinetti ME (1999) Drugs and falls in older people: a systematic review and meta-analysis: I. Psychotropic drugs. J Am Geriatr Soc 47:30-39.

9. Woolcott JC, Richardson KJ, Wiens MO, Patel B, Marin J, Khan KM, Marra CA (2009) Meta-analysis of the impact of 9 medication classes on falls in elderly persons. Arch Intern Med 169:1952-1960.

10. Wu Q, Bencaz AF, Hentz JG, Crowell MD (2012) Selective serotonin reuptake inhibitor treatment and risk of fractures: a meta-analysis of cohort and case-control studies. Osteoporos Int 23:365-375.

11. Rabenda V, Nicolet D, Beaudart C, Bruyere O, Reginster JY (2013) Relationship between use of antidepressants and risk of fractures: a meta-analysis. Osteoporos Int 24:121-137.

12. Ray WA, Griffin MR, Malcolm E (1991) Cyclic antidepressants and the risk of hip fracture. Arch Intern Med 151:754-756. 
13. Coupland C, Dhiman P, Morriss R, Arthur A, Barton G, Hippisley-Cox J (2011) Antidepressant use and risk of adverse outcomes in older people: population based cohort study. BMJ 343:d4551.

14. Eom CS, Lee HK, Ye S, Park SM, Cho KH (2012) Use of selective serotonin reuptake inhibitors and risk of fracture: a systematic review and meta-analysis. J Bone Miner Res 27:1186-1195.

15. Diem SJ, Blackwell TL, Stone KL, Yaffe K, Haney EM, Bliziotes MM, Ensrud KE (2007) Use of antidepressants and rates of hip bone loss in older women: the study of osteoporotic fractures. Arch Intern Med $167: 1240-1245$.

16. Rizzoli R, Cooper C, Reginster JY, Abrahamsen B, Adachi JD, Brandi ML, Bruyere O, Compston J, Ducy P, Ferrari S, Harvey NC, Kanis JA, Karsenty G, Laslop A, Rabenda V, Vestergaard P (2012) Antidepressant medications and osteoporosis. Bone 51:606-613.

17. Schwan S, Hallberg P (2009) SSRIs, bone mineral density, and risk of fractures--a review. Eur Neuropsychopharmacol 19:683-692.

18. (2015) American Geriatrics Society 2015 Updated Beers Criteria for Potentially Inappropriate Medication Use in Older Adults. J Am Geriatr Soc 63:2227-2246.

19. Gebara MA, Lipsey KL, Karp JF, Nash MC, Iaboni A, Lenze EJ (2014) Cause or Effect? Selective Serotonin Reuptake Inhibitors and Falls in Older Adults: A Systematic Review. Am J Geriatr Psychiatry. 20. Gebara MA, Shea ML, Lipsey KL, Teitelbaum SL, Civitelli R, Muller DJ, Reynolds CF, 3rd, Mulsant BH, Lenze EJ (2014) Depression, antidepressants, and bone health in older adults: a systematic review. J Am Geriatr Soc 62:1434-1441.

21. The 3C Study Group (2003) Vascular factors and risk of dementia: Design of the three city study and baseline characteristics of the study population. Neuroepidemiology 22:316-325.

22. Noize P, Bazin F, Dufouil C, Lechevallier-Michel N, Ancelin ML, Dartigues JF, Tzourio C, Moore N, Fourrier-Reglat A (2009) Comparison of health insurance claims and patient interviews in assessing drug use: data from the Three-City (3C) Study. Pharmacoepidemiol Drug Saf 18:310-319.

23. Noize P, Bazin F, Pariente A, Dufouil C, Ancelin ML, Helmer C, Moore N, Fourrier-Reglat A (2012) Validity of chronic drug exposure presumed from repeated patient interviews varied according to drug class. J Clin Epidemiol 65:1061-1068.

24. Barberger-Gateau P, Rainville C, Letenneur L, Dartigues JF (2000) A hierarchical model of domains of disablement in the elderly: a longitudinal approach. Disabil Rehabil 22:308-317. 
25. Rosow I, Breslau N (1966) A Guttman health scale for the aged. J Gerontol B Psychol Sci Soc Sci 21:556-559.

26. Lawton MP, Brody EM (1969) Assessment of older people: self-maintaining and instrumental activities of daily living. Gerontologist 9:179-186.

27. Katz S, Downs TD, Cash HR, Grotz RC (1970) Progress in development of the index of ADL. Gerontologist 10:20-30.

28. Folstein MF, Folstein SE, McHugh PR (1975) "Mini-mental state". A practical method for grading the cognitive state of patients for the clinician. J Psychiatr Res 12:189-198.

29. Radloff L (1977) The CES-D scale: a self-report depression scale for research in the general population. Applied Pyschological Measurement 1:385-401.

30. Sheehan DV, Lecrubier Y, Sheehan KH, Amorim P, Janavs J, Weiller E, Hergueta T, Baker R, Dunbar GC (1998) The Mini-International Neuropsychiatric Interview (M.I.N.I.): the development and validation of a structured diagnostic psychiatric interview for DSM-IV and ICD-10. J Clin Psychiatry 59 Suppl 20:22-33;quiz 34-57.

31. Lawlor DA, Patel R, Ebrahim S (2003) Association between falls in elderly women and chronic diseases and drug use: cross sectional study. BMJ 327:712-717.

32. Thiebaut AC, Benichou J (2004) Choice of time-scale in Cox's model analysis of epidemiologic cohort data: a simulation study. Stat Med 23:3803-3820.

33. Arfken CL, Wilson JG, Aronson SM (2001) Retrospective review of selective serotonin reuptake inhibitors and falling in older nursing home residents. Int Psychogeriatr 13:85-91.

34. Ensrud KE, Blackwell TL, Mangione CM, Bowman PJ, Whooley MA, Bauer DC, Schwartz AV, Hanlon JT, Nevitt MC (2002) Central nervous system-active medications and risk for falls in older women. J Am Geriatr Soc 50:1629-1637.

35. Richards JB, Papaioannou A, Adachi JD, Joseph L, Whitson HE, Prior JC, Goltzman D (2007) Effect of selective serotonin reuptake inhibitors on the risk of fracture. Arch Intern Med 167:188-194.

36. Topiwala A, Chouliaras L, Ebmeier KP (2014) Prescribing selective serotonin reuptake inhibitors in older age. Maturitas 77:118-123.

37. Grimsley SR, Jann MW (1992) Paroxetine, sertraline, and fluvoxamine: new selective serotonin reuptake inhibitors. Clin Pharm 11:930-957. 
38. Ensrud KE, Blackwell TL, Ancoli-Israel S, Redline S, Yaffe K, Diem S, Claman D, Stone KL (2006)

Use of selective serotonin reuptake inhibitors and sleep disturbances in community-dwelling older women. J Am Geriatr Soc 54:1508-1515.

39. (2011) Summary of the Updated American Geriatrics Society/British Geriatrics Society clinical practice guideline for prevention of falls in older persons. J Am Geriatr Soc 59:148-157.

40. Richa S, Yazbek JC (2010) Ocular adverse effects of common psychotropic agents: a review. CNS Drugs 24:501-526.

41. Rabenda V, Bruyere O, Reginster JY (2012) Risk of nonvertebral fractures among elderly postmenopausal women using antidepressants. Bone 51:674-679.

42. Moura C, Bernatsky S, Abrahamowicz M, Papaioannou A, Bessette L, Adachi J, Goltzman D, Prior J, Kreiger N, Towheed T, Leslie WD, Kaiser S, Ioannidis G, Pickard L, Fraser LA, Rahme E (2014)

Antidepressant use and 10-year incident fracture risk: the population-based Canadian Multicentre Osteoporosis Study (CaMoS). Osteoporos Int 25:1473-1481.

43. Prieto-Alhambra D, Petri H, Goldenberg JS, Khong TP, Klungel OH, Robinson NJ, de Vries F (2014) Excess risk of hip fractures attributable to the use of antidepressants in five European countries and the USA. Osteoporos Int 25:847-855.

44. Torres MJ, Feart C, Samieri C, Dorigny B, Luiking Y, Berr C, Barberger-Gateau P, Letenneur L (2015) Poor nutritional status is associated with a higher risk of falling and fracture in elderly people living at home in France: the Three-City cohort study. Osteoporos Int 26:2157-2164.

45. Fidalgo S, Ivanov DK, Wood SH (2013) Serotonin: from top to bottom. Biogerontology 14:21-45. 46. Austin PC (2014) The use of propensity score methods with survival or time-to-event outcomes: reporting measures of effect similar to those used in randomized experiments. Stat Med 33:1242-1258. 
Table 1. Baseline Characteristics and Risk of Falls over 4 Years, n=6599

\begin{tabular}{|c|c|c|c|c|c|c|}
\hline \multirow[b]{3}{*}{ Categorical variables } & \multicolumn{2}{|c|}{ Non fallers } & \multicolumn{2}{|c|}{ Fallers } & \multirow[b]{3}{*}{$\operatorname{HR}[95 \% \mathrm{CI}]^{\mathrm{a}}$} & \multirow[b]{3}{*}{$P$ value } \\
\hline & $\mathrm{N}=53$ & & $\mathrm{~N}=1$ & & & \\
\hline & $\mathrm{n}$ & $\%$ & $\mathrm{n}$ & $\%$ & & \\
\hline Sex (male) & 2282 & 42.85 & 364 & 28.59 & & $<0.0001^{\mathrm{b}}$ \\
\hline \multicolumn{7}{|l|}{ Smoking } \\
\hline Never & 3185 & 59.80 & 800 & 62.84 & - & \\
\hline Former & 1847 & 34.68 & 416 & 32.68 & $1.27[1.11 ; 1.45]$ & 0.0007 \\
\hline Current & 294 & 5.52 & 57 & 4.48 & $1.12[0.85 ; 1.47]$ & 0.41 \\
\hline
\end{tabular}

Body Mass Index $\left(\mathrm{kg} / \mathrm{m}^{2}\right)$

Normal $(<25)$
Overweight $(25-30)$
Obese $(\geq 30)$

MMSE

$$
\begin{aligned}
& \geq 26 \\
& <26
\end{aligned}
$$

Hierarchical disability indicator

Fully independent
Mild disability
Moderate to severe disability

Visual impairment ${ }^{\mathrm{c}}(\mathrm{n}=6266)$

Hearing impairment ${ }^{\mathrm{d}}$

Difficulties standing up from a chair

Poor balance during walking $(n=6573)$

Osteo-articular pain

Orthostatic hypotension $(\mathrm{n}=5608)$

Low standing blood pressure $(n=5624)$

Fear of falling

Daytime sleepiness $(n=6162)$

$\begin{array}{rrrrrr}2529 & 47.48 & 602 & 47.29 & - & \\ 2105 & 39.52 & 509 & 39.98 & 1.14[1.01 ; 1.29] & 0.03 \\ 692 & 12.99 & 162 & 12.73 & 1.12[0.94 ; 1.33] & 0.20\end{array}$

$\begin{array}{llll}4666 & 87.61 & 1078 \quad 84.68\end{array}$

$\begin{array}{llll}660 & 12.39 & 195 & 15.32\end{array}$

$1.16[1.00 ; 1.36]$

0.05

$\begin{array}{rrrrrrr}3196 & 60.01 & 593 & 46.58 & - & \\ 1881 & 35.32 & 551 & 43.28 & 1.09[0.96 ; 1.23] & 0.19 \\ 249 & 4.68 & 129 & 10.13 & 1.39[1.13 ; 1.71] & 0.002 \\ 692 & 13.66 & 204 & 16.99 & 1.02[0.88 ; 1.19] & 0.78 \\ 325 & 6.10 & 116 & 9.11 & 1.22[1.00 ; 1.48] & 0.05 \\ 535 & 10.05 & 208 & 16.34 & 1.34[1.15 ; 1.55] & 0.0002 \\ 848 & 15.96 & 356 & 28.23 & 1.52[1.34 ; 1.72] & <0.0001 \\ 958 & 17.99 & 287 & 22.55 & 1.21[1.06 ; 1.38] & 0.006 \\ 565 & 12.40 & 132 & 12.57 & 0.96[0.80 ; 1.16] & 0.70 \\ 93 & 2.03 & 29 & 2.75 & 1.17[0.81 ; 1.70] & 0.40 \\ 860 & 16.15 & 353 & 27.73 & 1.39[1.22 ; 1.57] & <0.0001 \\ 813 & 16.28 & 252 & 21.59 & 1.34[1.16 ; 1.55] & <0.0001\end{array}$




\begin{tabular}{|c|c|c|c|c|c|c|}
\hline \multirow[b]{3}{*}{ Categorical variables } & \multicolumn{2}{|c|}{ Non fallers } & \multicolumn{2}{|c|}{ Fallers } & \multirow[b]{3}{*}{$\operatorname{HR}[95 \% \mathrm{CI}]^{\mathrm{a}}$} & \multirow[b]{3}{*}{$P$ value } \\
\hline & \multicolumn{2}{|c|}{$N=5326$} & \multicolumn{2}{|c|}{$\mathrm{N}=1273$} & & \\
\hline & $\mathrm{n}$ & $\%$ & $\mathrm{n}$ & $\%$ & & \\
\hline Time since first $\mathrm{MDE} \geq 2$ years & 368 & 6.91 & 111 & 8.72 & $1.22[0.99 ; 1.50]$ & 0.06 \\
\hline Benzodiazepine use & 935 & 17.56 & 290 & 22.78 & $1.11[0.97 ; 1.26]$ & 0.14 \\
\hline Other CNS drugs ${ }^{\mathrm{e}}$ & 154 & 2.89 & 60 & 4.71 & $1.45[1.12 ; 1.88]$ & 0.005 \\
\hline Number of other medications $\geq 5$ & 1794 & 33.68 & 558 & 43.83 & $1.24[1.11 ; 1.39]$ & 0.0002 \\
\hline Continuous variables & Median & IQR & Median & IQR & $\operatorname{HR}[95 \% \mathrm{CI}]^{*}$ & $\mathrm{P}$ value \\
\hline Age (years) & 73 & $69-77$ & 75 & $\overline{70-79}$ & & $<0.0001^{\mathrm{b}}$ \\
\hline Sitting systolic blood pressure $(\mathrm{cm} \mathrm{Hg})$ & 14.6 & $13-16$ & 14.4 & $13-16$ & $0.96[0.93 ; 0.99]$ & 0.003 \\
\hline Number of cardiovascular diseases ${ }^{\mathrm{f}}$ & 0 & $0-1$ & 0 & $0-1$ & $1.09[1.02 ; 1.16]$ & 0.007 \\
\hline Depressive symptomatology (CES-D & 7 & $3-13$ & 9 & $5-16$ & $1.01[1.01 ; 1.02]$ & $<0.0001$ \\
\hline score) & & & & & & \\
\hline
\end{tabular}

${ }^{\mathrm{a}}$ Cox model adjusted for sex, center and age

${ }^{\mathrm{b}}$ Chi square test for sex and Wilcoxon test for age

${ }^{c}$ Visual impairment defined as having a corrected near visual acuity (Parinaud scale) of less than 2 or difficulties recognizing a familiar face at 4 meters.

${ }^{\mathrm{d}}$ Hearing impairment defined as deafness or only able to hear a conversation when a single person speaks loudly.

${ }^{\mathrm{e}}$ Anti-Parkinson, antiepileptic and psycholeptic drugs

${ }^{\mathrm{f}}$ Cardiovascular diseases include stroke, angina pectoris, myocardial infarction, cardio-vascular surgery, arrhythmia, heart failure, and peripheral artery disease; $73.1 \%$ of participants did not declare a cardiovascular disease, $18.0 \%$ had only one cardiovascular disease

CES-D: Center for Epidemiologic Studies-Depression scale, CI: confidence interval, CNS: central nervous system, HR: Hazard ratio, IQR: inter quartile range, MDE major depressive episode, MMSE: Mini Mental State Examination 
Table 2. Baseline Characteristics and Risk of Fractures over 4 Years, $n=6823$

\begin{tabular}{|c|c|c|c|c|c|c|}
\hline \multirow[b]{3}{*}{ Categorical variables ${ }^{\mathrm{a}}$} & \multicolumn{2}{|c|}{ No Fracture } & \multicolumn{2}{|c|}{ Fracture } & & \\
\hline & \multicolumn{2}{|c|}{$\mathrm{N}=6173$} & \multicolumn{2}{|c|}{$\mathrm{N}=650$} & & \\
\hline & $\mathrm{n}$ & $\%$ & $\mathrm{n}$ & $\%$ & $\mathrm{HR}[95 \% \mathrm{CI}]^{\mathrm{b}} \mathrm{F}$ & value \\
\hline Sex (male) & 2599 & 42.10 & 159 & 24.5 & & $<0.0001^{\mathrm{c}}$ \\
\hline \multicolumn{7}{|l|}{ Smoking } \\
\hline Never & 3728 & 60.39 & 426 & 65.54 & \multicolumn{2}{|l|}{ - } \\
\hline Former & 2109 & 34.16 & 193 & 29.69 & $1.29[1.06 ; 1.57]$ & 0.01 \\
\hline Current & 336 & 5.44 & 31 & 4.77 & $1.20[0.83 ; 1.74]$ & 0.33 \\
\hline Difficulties standing up from a chair & 720 & 11.68 & 107 & 16.51 & $1.17[0.95 ; 1.45$ & 0.14 \\
\hline Poor balance during walking $(\mathrm{n}=6786)$ & 1154 & 18.79 & 166 & 25.78 & $1.17[0.98 ; 1.41]$ & 0.08 \\
\hline Osteo-articular pains & 1146 & 18.56 & 145 & 22.31 & $1.17[0.97 ; 1.41]$ & 0.10 \\
\hline Time since first $\mathrm{MDE} \geq 2$ years & 425 & 6.88 & 64 & 9.85 & $1.41[1.07 ; 1.86]$ & 0.01 \\
\hline Benzodiazepine use & 1132 & 18.34 & 163 & 25.08 & $1.20[1.00 ; 1.43]$ & 0.05 \\
\hline Other CNS drugs ${ }^{\mathrm{d}} \|$ & 189 & 3.06 & 32 & 4.92 & $1.52[1.06 ; 2.16]$ & 0.02 \\
\hline Anti-osteoporosis drugs & 614 & 9.95 & 110 & 16.92 & $1.33[1.08 ; 1.64]$ & 0.008 \\
\hline \multicolumn{7}{|l|}{ Corticosteroid use } \\
\hline No & 5882 & 95.29 & 605 & 93.08 & & \\
\hline Oral & 88 & 1.43 & 17 & 2.62 & $1.62[1.00 ; 2.62]$ & 0.05 \\
\hline Inhaled & 203 & 3.29 & 28 & 4.31 & $1.33[0.91 ; 1.95]$ & 0.14 \\
\hline Continuous variables & Median & IQR & Median & IQR & $\mathrm{HR}[95 \% \mathrm{CI}]^{*}$ & $P$ value \\
\hline Age (years) & 73 & $69-77$ & 74 & $71-78$ & & $<0.0001^{c}$ \\
\hline
\end{tabular}

\footnotetext{
${ }^{a}$ All other variables in table 1 are non significant $(p>0.20)$ as well as hormonal replacement therapy in women

${ }^{\mathrm{b}}$ Cox model adjusted for sex, center and age

${ }^{\mathrm{c}}$ Chi square test for sex and Wilcoxon test for age

${ }^{\mathrm{d} A n t i-P a r k i n s o n, ~ a n t i e p i l e p t i c ~ a n d ~, ~ p s y c h o l e p t i c ~ d r u g s ~}$

CI: confidence interval, CNS: central nervous system, HR: Hazard ratio, IQR: inter quartile range, MDE major depressive episode
} 
Table 3. Four-year Risk of Falls and SSRI Antidepressant Use at Baseline

\begin{tabular}{|c|c|c|c|c|c|c|}
\hline & & & \multicolumn{2}{|l|}{ Model $0^{\mathrm{a}}$} & \multicolumn{2}{|l|}{ Model $1^{b}$} \\
\hline & fallers & & $\operatorname{HR}[95 \% \mathrm{CI}]$ & $\mathrm{P}$ value & $\mathrm{HR}[95 \% \mathrm{CI}]$ & $P$ value \\
\hline \multicolumn{7}{|l|}{ SSRI use $(\mathrm{n}=6599)$} \\
\hline No antidepressant & 5196 & 1202 & & & & \\
\hline SSRI & 130 & 71 & $1.84[1.45 ; 2.35]$ & $<0.0001$ & $1.58[1.23 ; 2.03]$ & 0.0003 \\
\hline \multicolumn{7}{|l|}{ SSRI drugs $(n=6589)^{\mathrm{c}}$} \\
\hline No antidepressant & 5196 & 1202 & & & & \\
\hline Fluoxetine & 48 & 23 & $1.58[1.04 ; 2.39]$ & 0.03 & $1.38[0.91 ; 2.10]$ & 0.14 \\
\hline Citalopram & 15 & 14 & $2.92[1.72 ; 4.95]$ & $<0.0001$ & $2.31[1.35 ; 3.96]$ & 0.002 \\
\hline Paroxetine & 48 & 23 & $1.75[1.16 ; 2.65]$ & 0.008 & $1.50[0.99 ; 2.28]$ & 0.06 \\
\hline Sertaline & 12 & 8 & $1.84[0.92 ; 3.70]$ & 0.16 & $1.65[0.82 ; 3.33]$ & 0.16 \\
\hline
\end{tabular}

SSRI usage patterns

$(\mathrm{n}=6118)$

$\begin{array}{lrrrrrr}\text { Never users }^{\mathrm{d}} & 4876 & 1094 & - & & & \\ \text { Continuing }^{\mathrm{e}} \| & 58 & 40 & 2.17[1.58 ; 2.99] & <0.0001 & 1.88[1.36 ; 2.61] & 0.0001 \\ \text { Discontinuing }^{\mathrm{f}} & 35 & 15 & 1.51[0.90 ; 2.52] & 0.12 & 1.27[0.76 ; 2.13] & 0.36\end{array}$

\footnotetext{
${ }^{\mathrm{a}}$ Model 0 adjusted for sex, age and center

${ }^{\mathrm{b}}$ Model 1 adjusted for age, center, sex, smoking, BMI, cognitive impairment, disability, benzodiazepines, other

CNS drugs, difficulties standing up from a chair, osteo-articular pains, fear of falling, time since first MDE, number of other medications, sitting systolic blood pressure, number of cardiovascular diseases, and CES-D score

${ }^{\mathrm{c}} 10$ participants taking fluvoxamine ( 3 fallers, 7 non fallers) were excluded due to small numbers.

${ }^{\mathrm{d}}$ No antidepressant at baseline nor at the 2- and 4- year follow-up

${ }^{\mathrm{e}} \mathrm{SSRI}$ used at baseline and at both follow-up visits

${ }^{\mathrm{f}} \mathrm{SSRI}$ used at baseline and not at the 2- and 4- year follow-up
} 
Table 4. Four-year Risk of Fracture and SSRI Antidepressant Use at Baseline

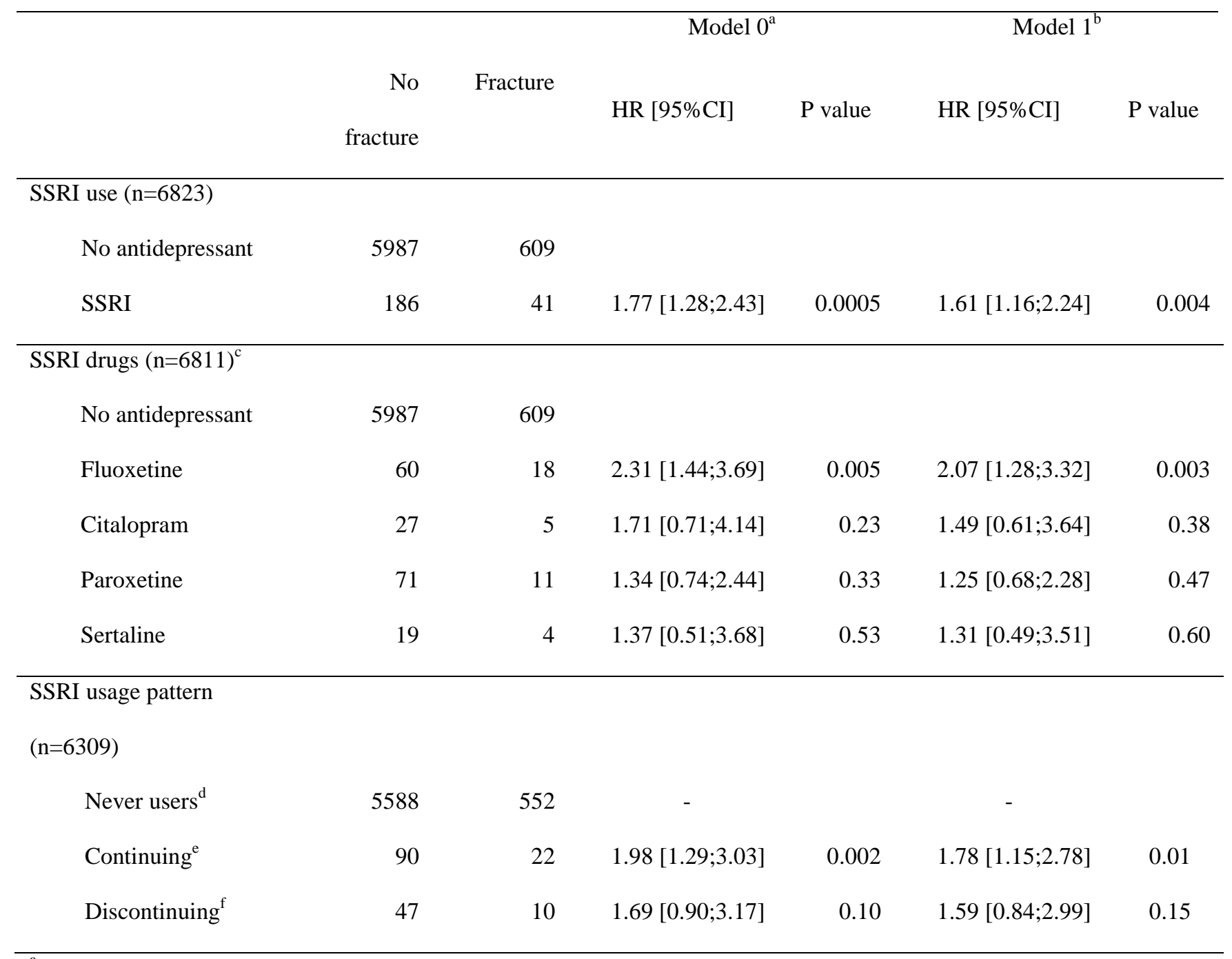

\footnotetext{
${ }^{\mathrm{a}}$ Model 0 adjusted for sex, age and center

${ }^{\mathrm{b}}$ Model 1 adjusted for age, center, sex, smoking, benzodiazepines, other CNS drugs, osteo-articular pains, time since first MDE, anti-osteoporosis drugs, and oral corticosteroids

${ }^{\mathrm{c}} 12$ participants taking fluvoxamine ( 3 fallers, 9 non fallers) were excluded due to small numbers

${ }^{\mathrm{d}}$ No antidepressant at baseline nor at the 2- and 4- year follow-up

${ }^{\text {e }}$ SSRI used at baseline and at both follow-up visits

${ }^{\mathrm{f}} \mathrm{SSRI}$ used at baseline and not at the 2- and 4- year follow-up
} 